\title{
Teaching Switching Converter Design Using Problem-Based Learning with Simulation of Characterization Modeling
}

\author{
Shun-Chung Wang ${ }^{\dagger}$, Yih-Chien Chen*, and Juing-Huei Su* \\ $\dagger *$ Dept. of Electronic Eng., the University of the Lunghwa, Taoyuan, Taiwan
}

\begin{abstract}
In this paper, teaching in a "switching converter (SC) design" course using problem-based learning (PBL) with dynamicbehavior-model simulation, given at Lunghwa University of Science and Technology (LHU), Taiwan, is proposed. The devised methodology encourages students to design and implement the SCs and regulate the controller's parameters in frequency domain by using 'sisitool' ('bode') in the MATLAB toolbox. The environment of PBL with converter characterization modeling and simulation reforms the learning outcome greatly and speeds up the teaching-learning process. To qualify and evaluate the learning achievements, a hands-on project cooperated with the continuous assessment approach is performed to modulate the teaching pace and learning direction in good time. Results from surveys conducted in the end of the course provided valuable opinions and suggestions for assessing and improving the learning effect of the proposed course successively. Positive feedbacks from the examinations, homework, questionnaires, and the answers to the lecturer's quizzes during class indicated that the presented pedagogy supplied more helpfulness to students in comparisons with conventional teaching paradigm, their learning accomplishments were better than expected as well.
\end{abstract}

Key Words: Characterization model simulation, Continuous assessment approach, Problem-based learning, Switching converter

\section{INTRODUCTION}

Nowadays, more than $75 \%$ of all generated electric power was refined by power electronic converters into various forms of power sources, which are optimally satisfied with the requirements of the different user loads. Recently, as the primary energy gradually exhaustion and the extensive demands for electronic products in miniaturization have made the design of the switching converter with sustainability and high conversion efficiency a prerequisite for engineers. Therefore, the importance of learning to develop state-of-the-art switching converters for engineers and students is recognized in these years owing to their far-reaching usage in electronic devices to supply dc or ac power sources [1]. This recognition has led to an increasing interest in providing power electronic courses at the senior undergraduate and the graduate levels in most universities [2]-[6]. Teaching a course in SC design is, however, a challenge since the fundamental field and prerequisite knowledge are quite comprehensive and multidisciplinary in nature [7], [8]. Furthermore, the teacher can not assume that all students enrolled in the class possess solid knowledge in so many areas. Considering the restriction for students on the available space and time, an effective teaching

\footnotetext{
Manuscript received May 3, 2010; revised Aug. 3, 2010

$\dagger$ Corresponding Author: wangsc@ mail.lhu.edu.tw

Tel: +886-2-8209-3211, Fax: +886-2-8209-9728, Lunghwa Univ.

* Dept. of Electronic Eng., the University of the Lunghwa, Taiwan
}

methodology cooperated with a well-equipped learning environment is needed for this course.

On the other hand, the introduction of computers in modernistic education in courses teaching/learning, laboratory exercises and research has become very essential. The SCs' circuit simulation and valid teaching processes are inevitable for teachers who want to prepare for students those design expertise. Without simulating testification and experimental observation, the theoretical analysis in subject matter is particularly hard to give an insight into the principles of converter operation. The SC's circuit simulation helps students to understand the complicated fundamentals and offers a superior preparation for the industrial practice [9], [10]. Thus, in an efficient situation, the student should be introduced to the SC's theory and conduct computer simulations, followed by designing their own converters and measuring them.

Positive effects and examples of successful application of problem-based learning (PBL) in engineering courses have been continuously proposed since the PBL is presented to the world over [11], [12]. PBL is defined as a teaching process which employs substantial problems to encourage students and that has a focus on student-centered activities [13]. The essences of constructivist and cognitivist are carried out effectively by the usage of the PBL paradigm. Based on the criterion of a need-to-know, the PBL approach creates a problem circumstance to conduct the learning activities [14] Learning in the PBL-based environment, students often collab- 
orate in groups or teams to clarify and specify the property of problems and endeavor to find the solved procedures. To obtain the needed and correct information, students are motivated to look for the available knowledge sources to solve the problem. The responsibility for learning is imposed on the learner during the knowledge quest. Students will learn and understand the subject matter better if they take part in some projects and practices actively. Hence, the PBL approach includes the learning of contents and social skills, emphasizes "learning to learn" and matches the constructivism fundamentals [3].

The PBL approach with behavior model simulation is introduced, in this paper, to enlighten the SC design course for senior students of the department of electrical engineering in the LHU, Taiwan. The proposed solution has the following advantages: the SC's models are constructed as block diagrams with an intuitive graphical interface in the Simulink environment; the controller's parameters are designed and verified by using frequency domain criteria in the MATLAB environment; this approach teaches students to develop the SC using systematic steps and hands-on circuits to meet the specified design criteria; simulations of dynamic model can validate students' idea or solutions for questions and design practices, but also to save their time in realizing phase. But the challenge to learn this course is that the prerequisite inside knowledge and threshold are higher than the other courses. This paper is organized as follows. Section II introduces the SC design practice, dynamical model simulation and learning mechanism used in the class. The theoretical backgrounds and lecture methods of the proposed course are described in Section III. Section IV presents the construction of behavior model in detail. A design case verification and the learning outcome assessment are given in Section $\mathrm{V}$ to show the effectiveness of the proposed pedagogy. Section VI concludes this paper.

\section{COURSE PANORAMA}

\section{A. Scheme of switching converter design practice}

Shown in Fig. 1 is a typical buck dc-dc switching converter with a feedback network [8]. From the designer's point of view, a practical SC design consists of several parts: switching converter topology selection, feedback controller design, magnetic component design and electromagnetic compatibility (EMC) etc. The design key points and procedures of each part inside the SC are summarized in Fig. 2. Among them, the magnetic component and EMC design depend on the realworld application, therefore is often not taken into account in university courses.

To learn the knowledge of a switching converter design, the students first have to know and discuss what the properties are for a well-designed SC. This includes the studies of why SC topologies are superior to linear regulators, and what the steady state, start-up and loading transient responses should be like, etc. When the students keep the SC architecture as shown in Fig. 1 in mind, the theoretical backgrounds concerning the steady state and dynamic analysis of the SCs, the feedback controller design facilities, the implementation arts of the evolved analog or digital feedback controllers, and

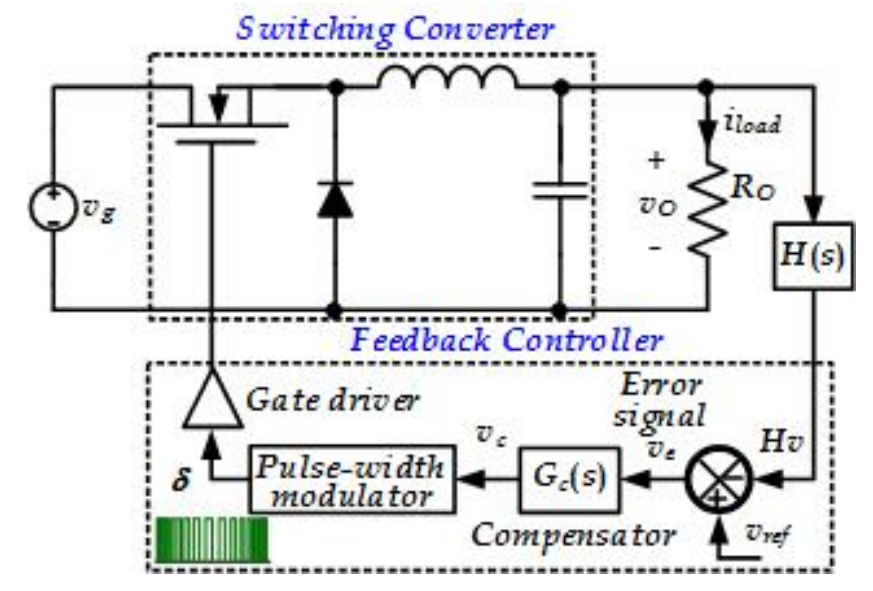

Fig. 1. A typical dc-dc switching converter system.

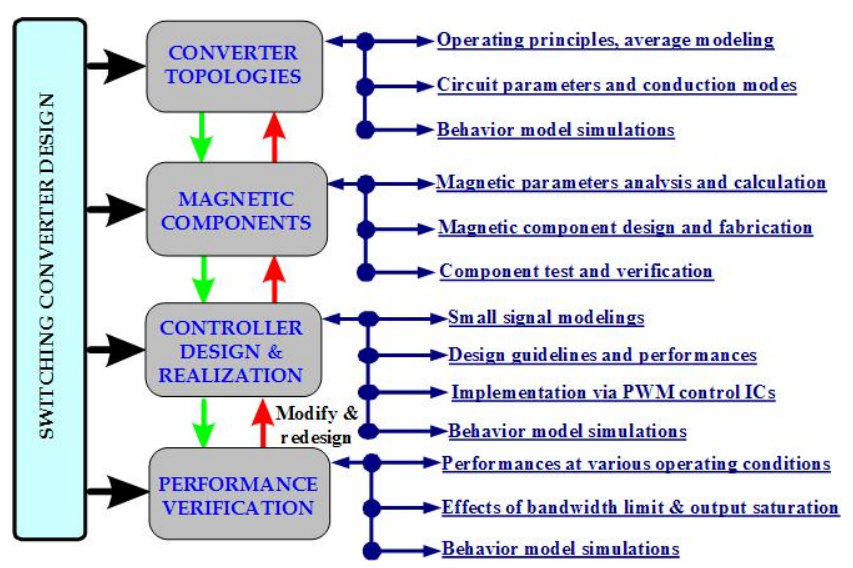

Fig. 2. Primary contents inside the SC design course.

the performance verification of the converter systems are then introduced step by step to students. The course materials, therefore, are divided into three portions as follows, 1) the modeling, design and selection of the SC topologies, 2) the derivation and simulation of control methods and criteria of controller design and realization, 3) the implementation and performance validation via Simulink behavior models.

\section{B. Simulations of dynamical modeling}

Simulations of dynamic models of the SC are suitable to predict converter steady-state and dynamical responses, as well as converter losses and efficiency. The motive of using MATLAB/Simulink to create system level behavior models is that, Simulink is a window-oriented, dynamics modeling, and software package constructed on top of the MATLAB numerical workspace. It is widely applied to various fields and courses design to assist the learning and simulation of some nonlinear and intricate systems [15], [16]. When the mathematical equations are available for the controlled plants, models are easily keyed in as block diagrams with an intuitive graphical interface. From mathematical presentations to Simulink behavior model creation, these procedures assist students in quickly certifying whether they can understand the correct operation of the SCs or not, but also fast learning how the feedback controllers affect the responses in closedloop system. In addition, the model parameters are entered in 
dialog menus and changed interactively during a simulation as a block. Therefore, students can run the simulation using the same concept of breadboarding the prototype of the SC. Especially, MATLAB toolbox of 'sisitool' ('bode') is helpful to the design, tuning and verification of the compensator inside the control loop in frequency domain to achieve optimal controller design purpose.

The SPICE [7]-[9] is also useful and popular application software in SC circuit simulation. The SPICE views mainly on device level in building the physical circuit for simulation. The intricacies of physical models, high computation burden and mass memory needed, however, make SPICE simulation during transient response time-consuming and encounter convergence problem unless some well-designed snubbers and device parameters are suitably defaulted [10]. Furthermore, several embedded facilities in SPICE, such as dc operating point and small-signal ac frequency analysis, are not available for switching converters, i.e. SPICE is unable to process the small-signal transfer functions of the SCs due to the switching nature of the power components. Thus, SPICE is not suitable for students who need to learn the system-level viewpoints in linear and even nonlinear feedback controller designs quickly. In this regard, provided that the dynamical models with SCs are built without too much exertion and provide accurate results as well, the MATLAB/Simulink simulation environment is very suitable to students to learn the controller design arts.

\section{Learning mechanism used in class}

In the aforementioned three main course contents, quizzes and the SC design and verification problems are raised during class to help students elaborate on earlier knowledge, propose logical arguments using the analysis tools, and study together to find the answer. This learning mechanism encourages students to take over the contents each other and refresh their memories after each lecture. Bonus scores are also proposed as incentives to animate each learning team to answer the quizzes. On the other hand, penalties are drawn up to prevent those groups of students from making wanton guesses which are not supported by any logical contention. From the student answers to the quizzes and SC design and certification problems, teachers will understand clearly how well they assimilate the knowledge behind the quizzes and problems. The teacher can hence tune the teaching pace and get chances to assist those students who do not learn well. In addition to the events of quizzes, problems and homework, the evaluations of the student learning outcome also contain midterm and final examinations. Finally, surveys performed in the end of the course to collect students' valuable opinions and suggestions, which can later be used to reform and rate the course successively.

During the class, handouts, supplementary materials, quizzes and open questions are provided to help students derive the averaged small-signal model and solve the handson issues step by step. Problems that students should learn to solve in groups or individually consist of quizzes in teachers, questions and homework for dynamical behavior and simulations, and design practices for feedback controllers to satisfy the prescribed criteria.

\section{ThEORETICAL BACKGROUNDS AND LECTURES}

The proposed course aims at enabling the students to understand the theoretical basics of various SC topologies, learning how to design a converter circuit using commercial available PWM ICs as well as gaining practical experiences and verifications via conducting the hands-on experiments. The first portion of this course introduces various topologies and operating principles of basic non-isolated and isolated dc-dc switching converters. Analyses of the steady-state and small-signal modeling under continuous or discontinuous conduction modes (CCM/DCM) are also derived, so that students can find out the quiescent operating point and create the coincident linearized average model.

When the desired specifications and design goals are defined and the topologies are suitably chosen and modeled, the skills of the feedback controller design in frequency domain, which consist of the second portion of the theoretical backgrounds, is prepared for students. The objective of this portion is to learn techniques for analysis and construction of Bode plots of the converter transfer functions to offer enough phase margin of the loop gain for the system transient response to be better behaved. Design-oriented analysis of the converter is utilized to develop transfer functions which allow element values to be chosen to meet the design specifications. In this phase, students need to acquire extra knowledge and physical insight into the converter behaviors. After this portion lectures, students should know how to design the controller and evaluate whether their controllers, under all operating conditions, can regulate the converter and provide good transient and steadystate responses or not.

During the performance verification session, predictions of the behavior model are compared to an implemented prototype. The quantitative estimation of the model performance should be able to judge whether specifications are matched under all conditions, thus computer simulation is well-suited to this work. The simulation of the created Simulink behavior model, therefore, is a suitable tool for students to quickly verify whether their knowledge and predictions regarding circuit operations are correct or not. These behavior models are fast, user friendly, and accurate enough compared with real circuits. However, students are asked in this phase to make their own circuits for different SC topologies and to present the design procedures as well as validate the measured results with theoretic derivation. The above design steps are repeatedly to modify and redesign the converter until the worst-case behaviors match specifications, or until the stability and reliability are acceptably high.

\section{Behavior Model Construct}

This Section presents the principle of how to construct the converter Simulink behavior model, and a generalized construction approach for the power stage and PWM control ICs in the SC is derived. The state-space averaging (SSA) approach is used to derive the converter quiescent dc and small-signal ac models [8]. Provided that the converter state equations are written, the small-signal model is obtained by SSA process and the corresponding Simulink behavior model is also obtained 


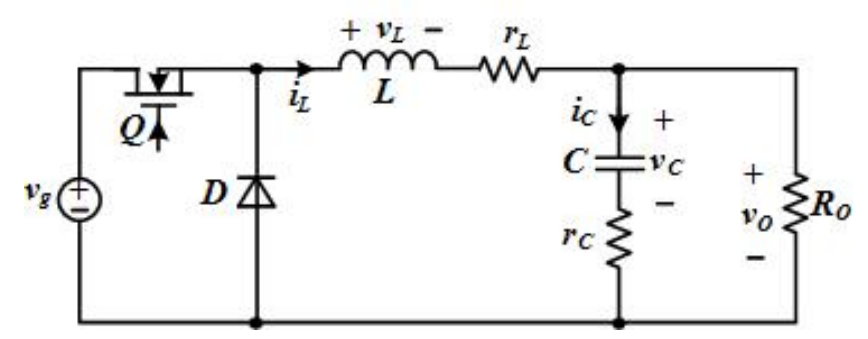

Fig. 3. Buck converter with non-ideal component effect.

accordingly. Take one typical converter circuits as examples to illustrate the fundamentals and know-how of the Simulink characterization model construction.

\section{A. Derivation of power stage with part nonidealities}

Shown in Fig. 3 is a buck converter with the component nonideality including the equivalent series resistances (ESR) $r_{L}$ and $r_{C}$ in the inductor and capacitor. Let the inductor current $i_{L}$ and capacitor voltage $v_{C}$ are the state variables. Assuming the buck converter operates in CCM. When the switch $Q$ is on, the state equation can be expressed as

$$
\begin{gathered}
\frac{d i_{L}}{d t}=\frac{-R_{O}\left(r_{L}+r_{C}\right)-r_{L} r_{C}}{L\left(R_{O}+r_{C}\right)} i_{L}+\frac{-R_{O}}{L\left(R_{O}+r_{C}\right)} v_{C}+\frac{1}{L} v_{g} \\
\frac{d v_{C}}{d t}=\frac{R_{O}}{C\left(R_{O}+r_{C}\right)} i_{L}+\frac{-1}{C\left(R_{O}+r_{C}\right)} v_{C} .
\end{gathered}
$$

When the switch $Q$ is off, the state equation can be written as

$$
\begin{gathered}
\frac{d i_{L}}{d t}=\frac{-R_{O}\left(r_{L}+r_{C}\right)-r_{L} r_{C}}{L\left(R_{O}+r_{C}\right)} i_{L}+\frac{-R_{O}}{L\left(R_{O}+r_{C}\right)} v_{C} \\
\frac{d v_{C}}{d t}=\frac{R_{O}}{C\left(R_{O}+r_{C}\right)} i_{L}+\frac{-1}{C\left(R_{O}+r_{C}\right)} v_{C} .
\end{gathered}
$$

The output voltage $v_{O}$ in both the circuit states is given as

$$
v_{O}=\frac{R_{O} r_{C}}{R_{O}+r_{C}} i_{L}+\frac{R_{O}}{R_{O}+r_{C}} v_{C}
$$

From the state equations and output voltage equation, (1)(5), the corresponding behavior model for power stage is constructed in Simulink environment as shown in Fig. 4. In addition, the built model can be masked into a subsystem in Simulink, and the users can employ a dialog window to change the circuit parameters during simulation easily.

\section{B. Derivation of compensated error amplifier (CEA)}

In spite of disturbances in input voltage or load or variations in part values, the concept behind the use of feedback controller is to construct an error compensator which can modulate the duty cycle automatically if needed to regulate the desired output voltage with acceptable accuracy. A typical controller block of a buck converter system is also shown in Fig. 1. A voltage divider with gain $H(s)$ is used to sense the output voltage, the sensor output signal $H(s) v_{O}(s)$ is compared with a reference input $v_{r e f}(s)$. The control objective is to minimize the error between the $H(s) v_{O}(s)$ and $v_{r e f}(s)$, so that output voltage can follow the reference input with good accuracy

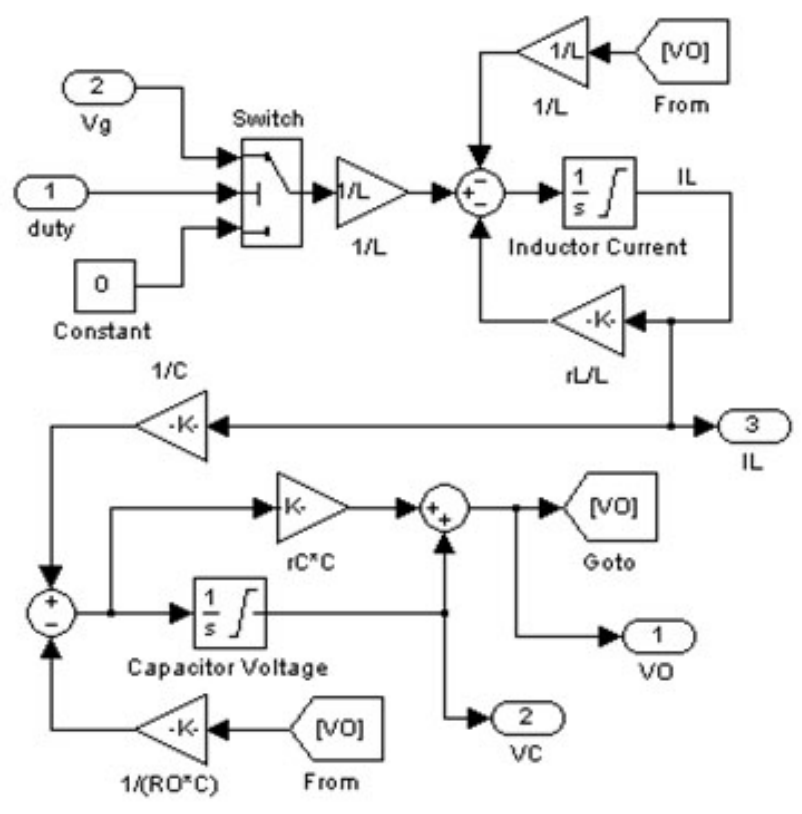

Fig. 4. The Simulink behavior model of buck converter.

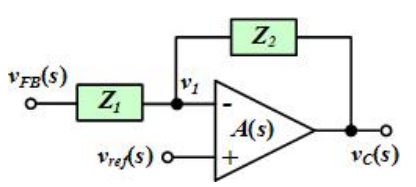

(a)

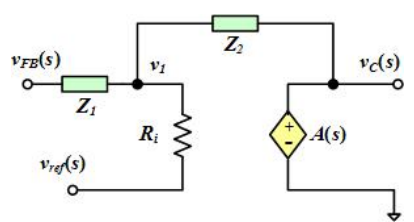

(b)
Fig. 5. Compensated error amplifier: (a) general compensator network; (b) equivalent circuit of (a).

by adjusting duty cycle properly. The error signal ve(s), in practice, is usually nonzero yet small. To obtain a stable control, a compensator network $G_{c}(s)$ should be added to provide adequate loop gain and phase margin for compensating the gain decay and phase shift caused by the power stage including output filter and the PWM modulator.

The general form and its equivalent circuit of a feedback controller that is constructed by an operating amplifier (OPA) are shown in Fig. 5. Assuming the input impedance of the OPA is infinite, the output voltage of the CEA is given by

$$
\begin{gathered}
v_{1}=\frac{Z_{2}}{Z_{1}+Z_{2}} v_{F B}+\frac{Z_{1}}{Z_{1}+Z_{2}} v_{C} \\
v_{C}=A(s)\left(v_{r e f}-v_{1}\right)
\end{gathered}
$$

where the open loop transfer function $A(s)$ of the OPA is approximated by using a first order low-pass filter and is presented as

$$
A(s)=G_{0} \frac{p}{s+p}
$$

whose pole is located at $-p$ and $G_{0}$ is dc gain. Using (6)-(8), one of the possible realization of such a Simulink behavior model for a generalized CEA is shown in Fig. 6. Effects of the output saturation and gain-bandwidth limits in practical OPA should be taken into account. This is important 


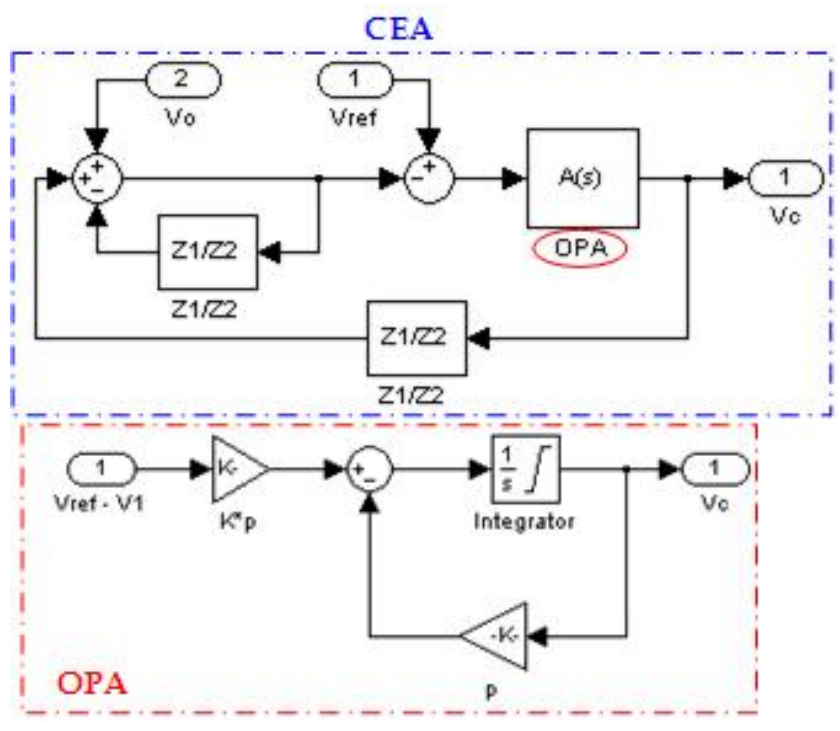

Fig. 6. The Simulink behavior model of the CEA.

to achieve well design and convergence simulation of the SC controller. According to the UC3525 datasheet [17], the frequency response and electrical characteristics in OPA shown the dc gain $G_{0}$ is about $75 \mathrm{~dB}$ and the pole $-p$ is located near $-2 \pi \times 200 \mathrm{~Hz}$. The output voltage range is $0.2 \mathrm{~V} \sim 5.6 \mathrm{~V}$. Here a question, 'how to find the dc gain and pole location of the OPA,' could be as a quiz in class for students to discuss and try to find the answer. Once the output saturation and gainbandwidth limits for the OPA are found, the upper bound and lower bound are inputted in the integrator function block to set the constraints accordingly.

\section{Derivation of voltage-mode PWM control IC}

Commercially available PWM ICs are widely used in constructing the feedback controller due to the features of low in price, convenience in use and ease to implement. Shown in Fig. 7 is the simplified function block diagram of the UC3525 [17]. Form Fig. 7, the UC3525 mainly consists of an error amplifier, a PWM comparator and an S-R flip-flop. The CEA has been created as shown in Fig. 6, and the error voltage is derived in the feedback system from the CEA that amplifies the difference between the output voltage and the reference voltage. The generated control signal is then compared to a sawtooth ramp to modulate the duty cycle of the power switch. The embedded flip-flop assures that only one PWM pulse is generated for each clock period. Combining the CEA model with the operating behavior constructed according to Fig. 7, the completed Simulink behavior model of the UC3525baed feedback controller is shown in Fig. 8. Eventually, the completed Simulink behavior model of the buck converter is constructed by integrating the two subsystems of the power stage and feedback controller into a whole system, as shown in Fig. 9.

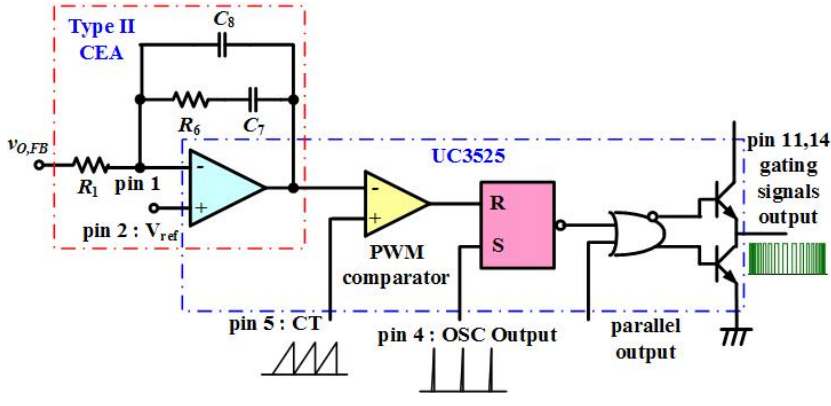

Fig. 7. Simplified function block diagram of UC3525.

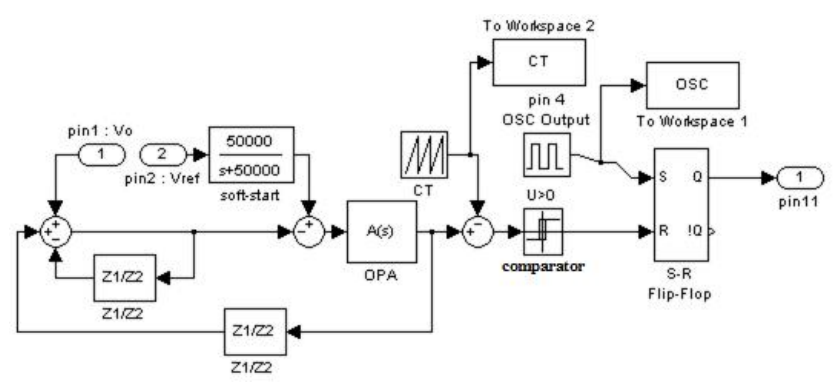

Fig. 8. Completed model of UC3525-baed controller.

\section{Example Demonstration And Course ASSESSMENT}

\section{A. Experimental verification}

Shown in Fig. 10 is the implemented circuit schematic of the buck converter example. The design specifications and power stage component values are: switching frequency $f_{s}$ is $50 \mathrm{kHz}$, input voltage $V_{g}$ is $15 \mathrm{~V}$, output voltage/current is $5 \mathrm{~V} / 3 \mathrm{~A}(15 \mathrm{~W})$, the inductance $L$ is $115 \mu \mathrm{H}$, the capacitance $C$ is $3300 \mu \mathrm{F}$, and the $r_{L}$ and $r_{C}$ are $0.1 \Omega$ and $0.3 \Omega$, respectively. The crossover frequency and phase margin of the designed controller system are selected at $6 \mathrm{kHz}$ and $55^{\circ}$ respectively to satisfy the stability criteria.

From the state equations (1) (5) and using SSA approach, the quiescent operating point (denoted by subscript ' 0 ') of the state variables $\mathrm{X}_{0}=\left[\begin{array}{ll}I_{L 0} & V_{C 0}\end{array}\right]^{T}$ and duty cycle $D_{0}$ can be solved by

$$
\left[\begin{array}{c}
\mathrm{X}_{0} \\
D_{0}
\end{array}\right]=\left[\begin{array}{cc}
\mathrm{A}_{1} & \left(\mathrm{~B}_{1}-\mathrm{B}_{2}\right) V_{g} \\
\mathrm{C}_{1} & 0
\end{array}\right]^{-1}\left[\begin{array}{c}
-\mathrm{B}_{2} V_{g} \\
V_{O}
\end{array}\right]
$$

where $A_{1}=A_{2}=\left[\begin{array}{cc}\frac{-R_{O}\left(r_{L}+r_{C}\right)-r_{L} r_{C}}{L\left(R_{O}+r_{C}\right)} & \frac{-R_{O}}{L\left(R_{O}+r_{C}\right)} \\ \overline{R_{O}} & \overline{C\left(R_{O}+r_{C}\right)} \\ C\left(R_{O}+r_{C}\right)\end{array}\right], B_{1}=$ $\left[\begin{array}{c}\frac{1}{L} \\ 0\end{array}\right], B_{2}=\left[\begin{array}{l}0 \\ 0\end{array}\right]$, and $C_{1}=C_{2}=\left[\begin{array}{ll}\frac{R_{O} r_{C}}{R_{O}+r_{C}} & \frac{R_{O}}{R_{O}+r_{C}}\end{array}\right]$. Performing perturbation and linearization to the state equations and neglecting the nonlinear terms, the small-signal ac model is obtained as

$$
\begin{gathered}
\dot{\tilde{\mathrm{x}}}=\mathrm{A}_{1} \tilde{\mathrm{x}}+\mathrm{B}_{\mathrm{cc}} \tilde{v}_{g}+\left(\mathrm{B}_{1}-\mathrm{B}_{2}\right) V_{g} \tilde{d} \\
\tilde{v}_{O}=\mathrm{C}_{1} \tilde{\mathrm{x}}
\end{gathered}
$$

where $B_{c c}=B_{1} D_{0}+B_{2}\left(1-D_{0}\right)$, and the quantities of small ac variation are represented by superscript ${ }^{\text {' } ~}$. Substituting the 


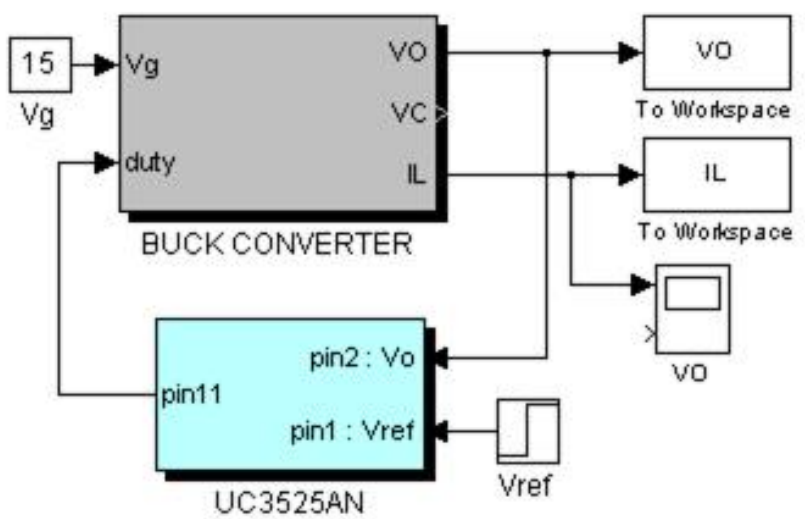

Fig. 9. Completed buck Simulink behavior model.

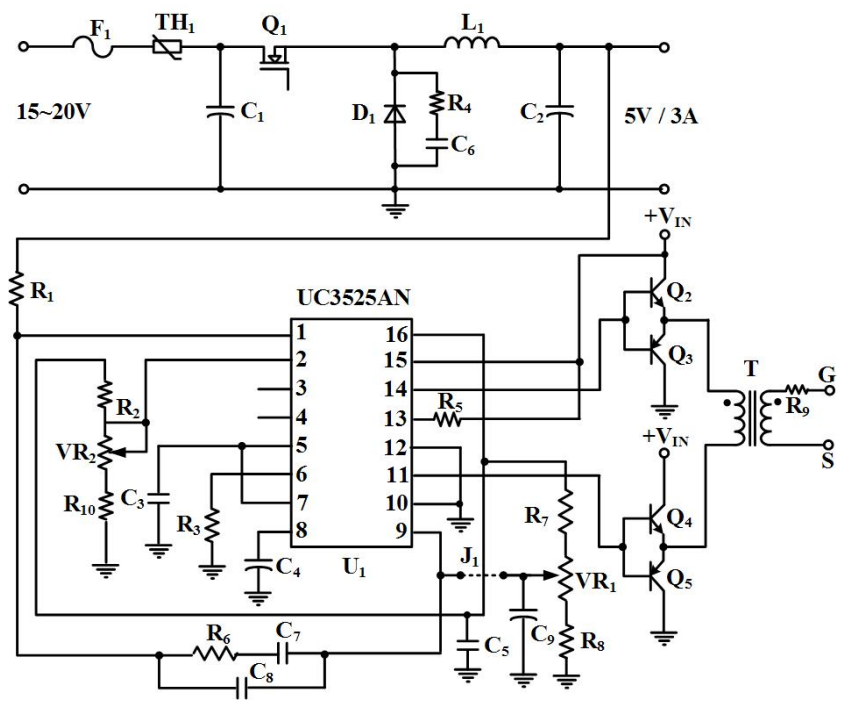

Fig. 10. Implemented circuit schematic.

element values into (9), the solved quiescent operating point is $I_{L 0}=0.25 \mathrm{~A}, V_{C 0}=5 \mathrm{~V}, D_{0}=0.33$. Form (10) and (11), with Laplace transfer, the control-to-output transfer function is derived as

$$
G_{v d}(s)=\frac{3849 s+3.9 \times 10^{7}}{s^{2}+1292 s+2.7 \times 10^{6}} .
$$

The CEA is used type II network as shown in Fig. 7; its transfer function is given as

$$
G_{c}(s)=\frac{0.22112 s+1}{s(0.0005712 s+0.0002)} .
$$

The sensor gain $H$ equals 1 , and the peak value of the sawtooth ramp $V_{M}$ is $3.6 \mathrm{~V}$. Using these corresponding parameters, the system open-loop and closed-loop transfer function can be calculated as Eq. (14) and (15), respectively.

$$
\begin{gathered}
G_{o l}(s)=\frac{4.3 s^{2}+47305 s+3.9 \times 10^{7}}{0.02 s^{3}+2.7 s^{2}+5613 s+1966} \\
G_{c l}(s)=\frac{4.3 s^{2}+47305 s+3.9 \times 10^{7}}{0.02 s^{4}+2.7 s^{3}+5629 s^{2}+170298 s+1.4 \times 10^{8}} .
\end{gathered}
$$

The MATLAB toolbox 'sistool' is used to demonstrate whether the implemented controller is well-designed or not.

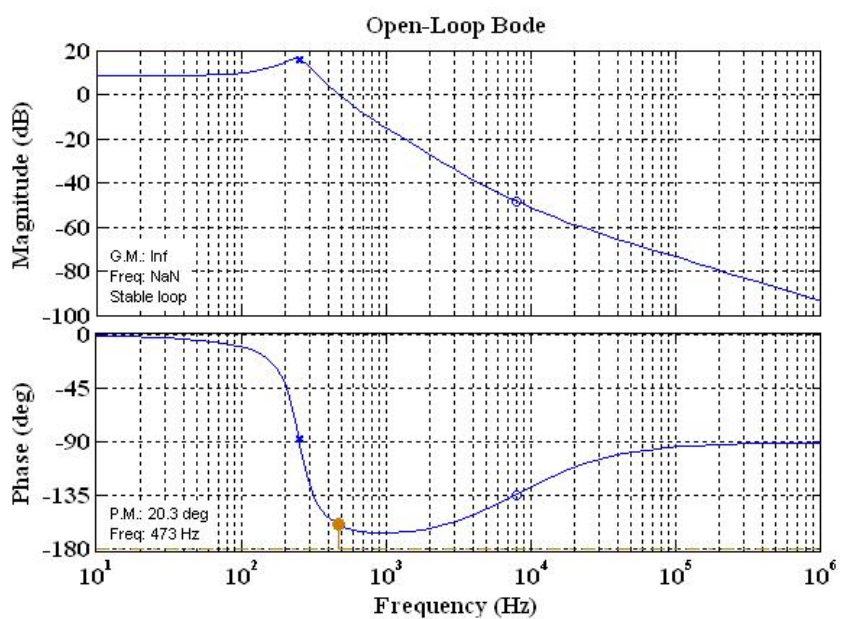

Fig. 11. Bode plot of open-loop transfer function.

Bode plots for uncompensated and compensated situations are plotted in Fig. 11 and 12, respectively. From the closedloop bode plot (Fig. 12); we can see that the phase margin and crossover frequency are obviously improved respectively from $20.3^{\circ}$ to $56.2^{\circ}$ and from $473 \mathrm{~Hz}$ to $5.75 \mathrm{kHz}$ by the compensation of the type II CEA. Adding a zero and a pole is equivalent to a Type II compensation circuit. The parameters of the compensation circuit can also be inputted by using the parameter setting dialog window in the Simulink environment. The students can then use the presented Simulink model to simulate this circuit. To verify the correctness of the proposed method, a prototype circuit as shown in Fig. 13 using the same parameters is also implemented.

The simulated and experimental results for inductor current and output voltage, under fixed load $\left(R_{O}=2.5 \Omega\right)$ and load disturbance $\left(R_{O}\right.$ change from $3.3 \Omega$ to $10 \Omega$ ) conditions, are shown in Fig. 14 and Fig. 15, respectively. On the fixed load test (Fig. 14), we can verify the start-up transient response (including rising time, maximum overshoot and settling time) and the steady-state response (including steady-state error). Maybe the start-up responses have a little difference between the simulated and measured waveforms due to the effects of the stray and parasitic components in the implemented circuit, but the steady-state portions are nearly in good tune to each other. On the load change test (Fig. 15), we can examine the robustness and reliability of the designed controller. It is noted that the Fig. 15 only shows the inspection of the load change moment. Because the disturbance is from heavy load (1.5A) to light load (0.5A), a small $v_{O}$ overshoot, induced by the ESR of the output filter capacitor, occurs at the change instant. However, the designed controller shows good voltage regulation and robustness against the load variation. It is not easy to predict how large the overshoot or undershoot of the startup and load change transient responses would be, because of the saturation effect of the OPA. Therefore, the behavior model simulations play a very important role in this course to assure students to know how the feedback controller is good to control the buck converter circuit, and save their time in trying and making errors. 


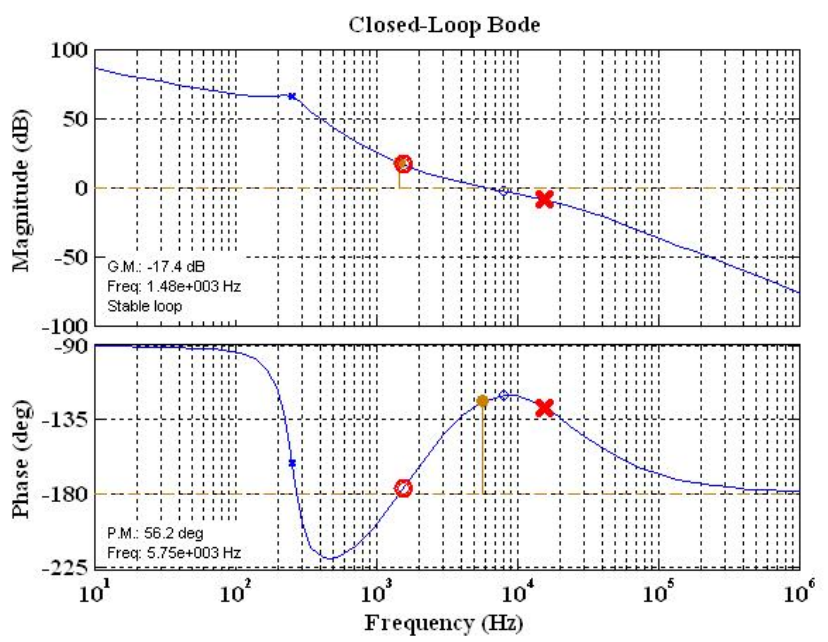

Fig. 12. Bode plot of close-loop transfer function.

\section{B. Assessment of learning achievement}

To assess the proposed SC design course, a comprehensive survey that was conducted to the class shortly before the end of the term, and a comparison of final examination scores between a previous class (97-1 semester) that did not use the teaching method and the current class (97-2 semester) that did use the proposed pedagogy. The anonymous questionnaire and results (with five point scale) is shown in Table I. The percentage comparison of the final term grades between $97-$ 1 and 97-2 semesters is shown in Fig. 16. According to the evaluation results, the proposed method has received a 4.42/5.0 rating, comparing with an average rating of 3.95/5.0 for electrical engineering courses at LHU, and the average exam score of the 97-2 semester is more progress than the previous semester 97-1. The opinions and suggestions from the student feedback are very positive with regard to the experiments provided in the assistance of the proposed Simulink model simulation. Majority of students felt that the final handson project enhanced their understanding of the theoretical material and made the course more interesting.

It is noted that the students who learn the techniques through discussions, finding answers to quizzes and problems show more interest in the course than those who learn the theory via traditional instruction approach. The average scores of the midterm and final examination also confirm this observation. Some of the students still think that the technology is too difficult to learn, although they have joined the discussions, and solved the problems with the other students. It is found at the end of the course that more than $80 \%$ of the students need some more time to digest those important ideas in the lecture notes and what the teacher explained during classes.

\section{CONCLUSIONS}

In this paper, the problem-based learning with system level behavior model simulation approach is proposed to help students to learn theories and implementations of the SC design course. The objective of the proposed scheme assists students to study and design the SC through simulation and to validate design performance through circuit realization. A

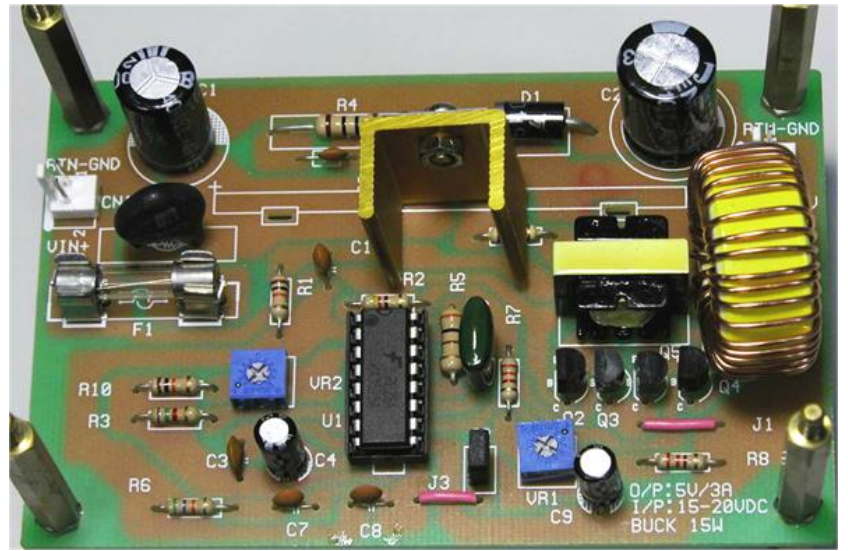

Fig. 13. The implemented prototype circuit.

TABLE I

QUESTIONNAIRE AND RESULTS

\begin{tabular}{|c|c|c|c|c|c|c|}
\hline Question & 1 & 2 & 3 & 4 & 5 & Avg. \\
\hline $\begin{array}{l}\text { 1. Are the course challenging and } \\
\text { interesting? }\end{array}$ & 1 & 1 & 5 & 8 & 25 & 4.38 \\
\hline $\begin{array}{l}\text { 2. Have you learned more than ex- } \\
\text { pected with this course? }\end{array}$ & 0 & 0 & 4 & 6 & 30 & 4.65 \\
\hline $\begin{array}{l}\text { 3. Using Simulink models to perform } \\
\text { power converter simulation and to an- } \\
\text { swer the question make me under- } \\
\text { stand the operating principles of dc } \\
\text { power converters }\end{array}$ & 1 & 3 & 6 & 10 & 20 & 4.13 \\
\hline $\begin{array}{l}\text { 4. Using Simulink models, I under- } \\
\text { stand the difference between the state- } \\
\text { space average models and the physical } \\
\text { circuits of a power converter. Further- } \\
\text { more, I know the reason why we use } \\
\text { the state-space average model. }\end{array}$ & 2 & 0 & 4 & 14 & 20 & 4.25 \\
\hline $\begin{array}{l}\text { 5. I know that when designing the } \\
\text { feedback controller of a power con- } \\
\text { verter, a small-signal transfer func- } \\
\text { tion under some dc operating points } \\
\text { should be used. }\end{array}$ & 1 & 1 & 3 & 15 & 20 & 4.30 \\
\hline $\begin{array}{l}\text { 6. I don't know that the phase margin } \\
\text { of the feedback controller should be } \\
\text { greater than zero to ensure that a } \\
\text { closed-loop system is stable. }\end{array}$ & 0 & 2 & 6 & 10 & 22 & 4.30 \\
\hline $\begin{array}{l}\text { 7. I know that the } 0 \mathrm{~dB} \text { cross over } \\
\text { frequency of the loop gain is approxi- } \\
\text { mately equals to the bandwidth of the } \\
\text { whole closed-loop system }\end{array}$ & 0 & 0 & 5 & 5 & 30 & 4.63 \\
\hline $\begin{array}{l}\text { 8. Do you have shortened the learning } \\
\text { time via the assistance of the Simulink } \\
\text { model simulation? }\end{array}$ & 0 & 1 & 4 & 12 & 23 & 4.43 \\
\hline $\begin{array}{l}\text { 9. Using Simulink models in this } \\
\text { course help me understand the operat- } \\
\text { ing principles of power converters and } \\
\text { verify the performance of a feedback } \\
\text { controller efficiently }\end{array}$ & 0 & 0 & 5 & 8 & 27 & 4.55 \\
\hline $\begin{array}{l}\text { 10. Please, provide an overall evalua- } \\
\text { tion on this course. }\end{array}$ & 0 & 0 & 2 & 15 & 23 & 4.53 \\
\hline
\end{tabular}

generalized MATLAB/Simulink behavior modeling techniques is constructed. Simulations of dynamic model are performed not only to verify students' idea or solutions for questions and design practices, but also to save their time in realization phase which satisfied the desired specifications.

Learning in switching converter design based on the auxiliary of the MATLAB/Simulink behavior model has been developed in this paper. To speed up the learning process, a problem-based learning approach with a hands-on project is 

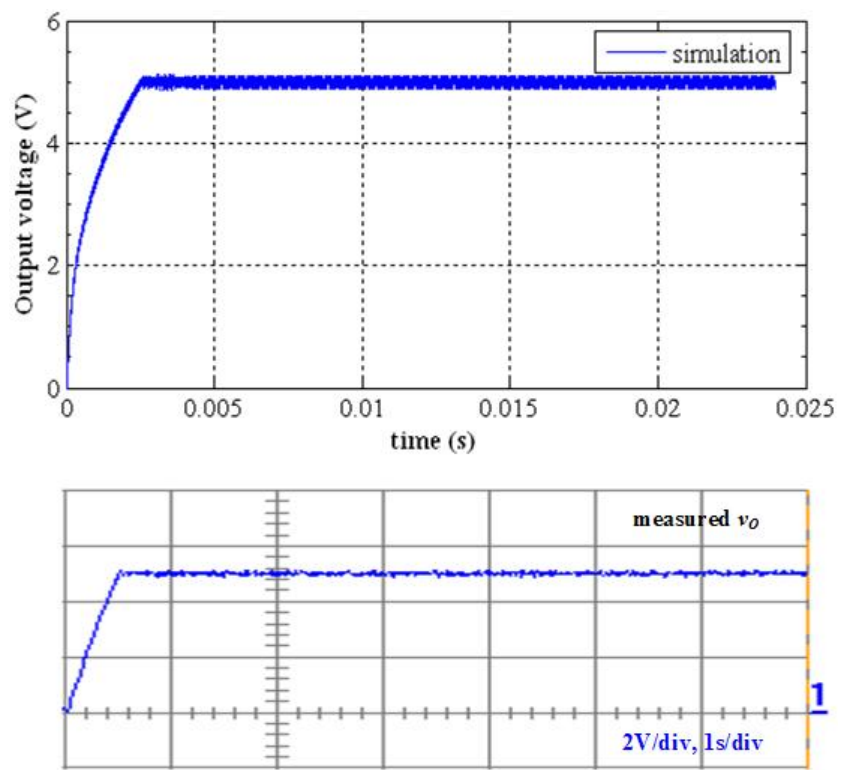

(a) Output voltage waveform.
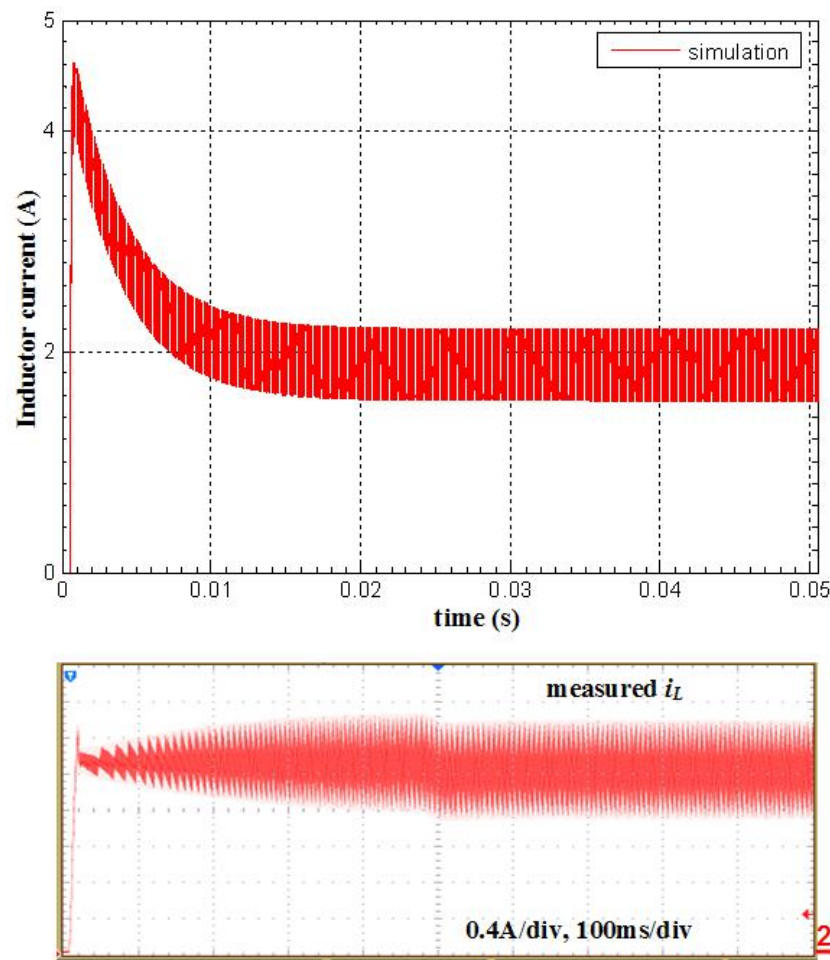

(b) Inductor current waveform.

Fig. 14. The simulation and experimental results of the fixed load responses $\left(R_{O}=2.5 \Omega\right)$.
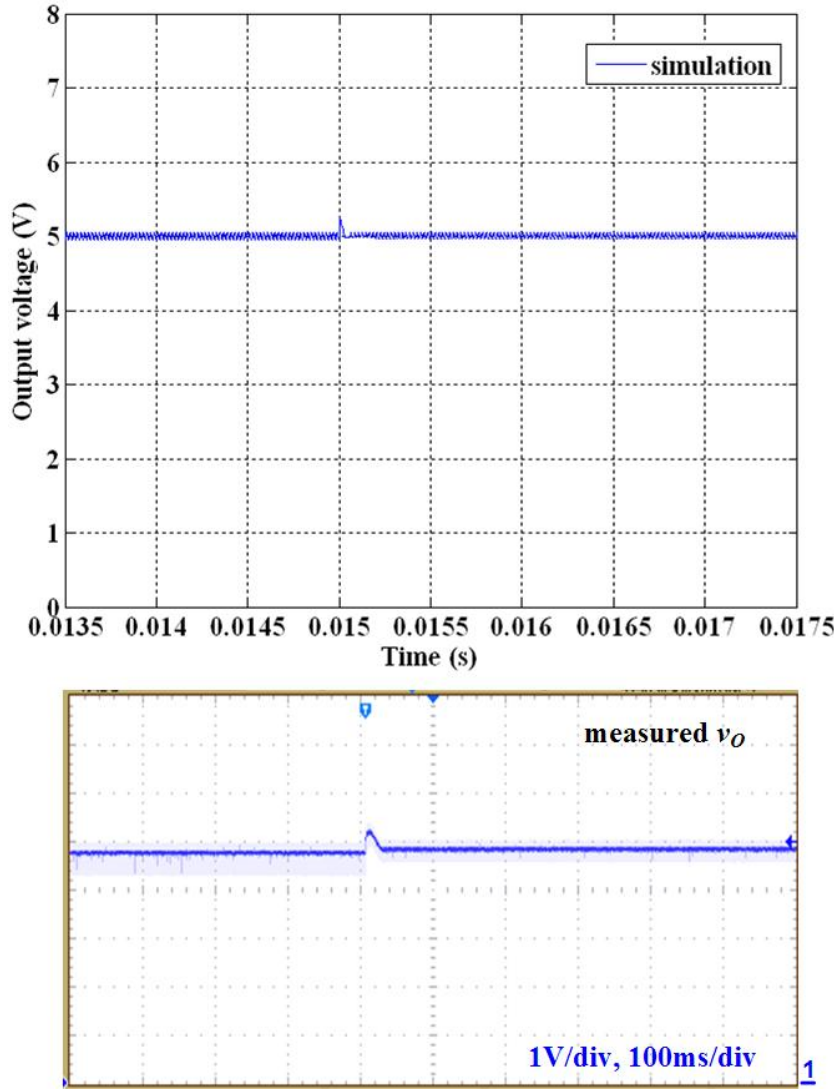

(a) Output voltage waveform.
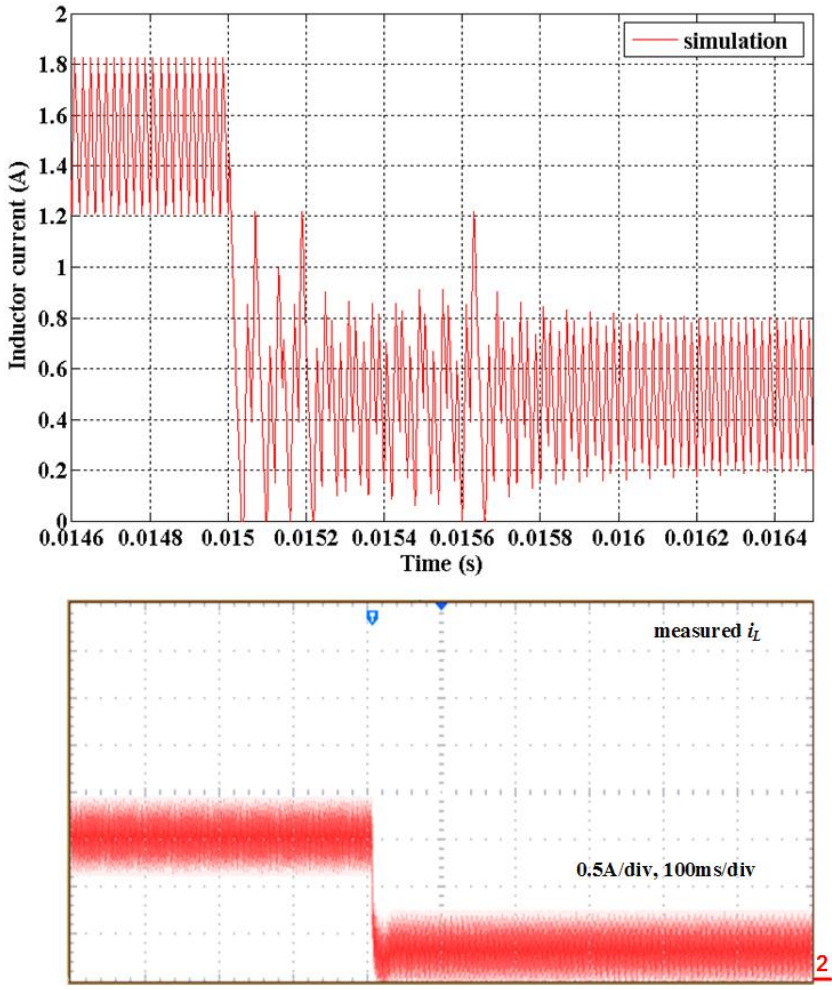

(b) Inductor current waveform

Fig. 15. The simulation and experimental results of load change (from $3.3 \Omega$ to $10 \Omega$ ). 


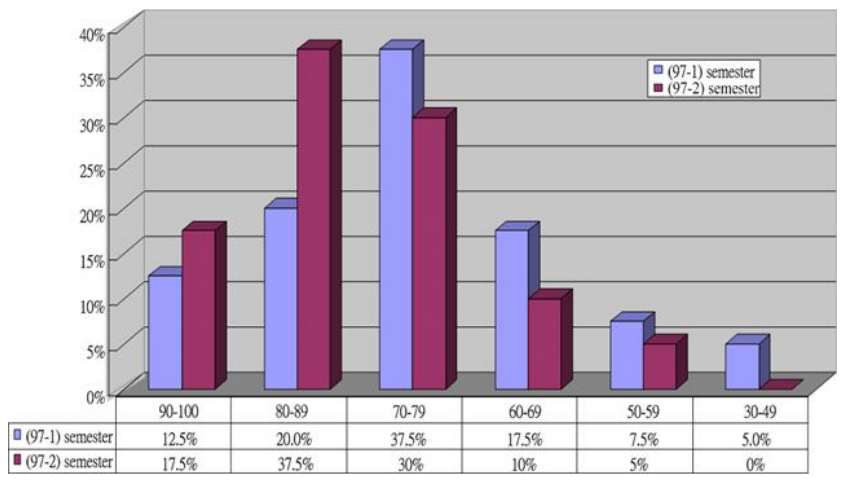

Fig. 16. Comparison of final exam scores of two semesters.

used to refine the switching converter design course. In order to qualify and promote the students' performance, the continuous assessment approach with real-time evaluation feedbacks is adopted to modify the teaching pace and direction in good time. A comprehensive survey is carried out to collect students' opinions for improving and assessing the course design. Positive feedbacks from the midterm and final examinations, the questionnaires, and the answers to the teacher's quizzes show that the presented pedagogy is very effective for students in learning switching converter design.

\section{ACKNOWLEDGMENT}

This work was supported by Ministry of Education, Taiwan, R.O.C., under research grant 99E-88-064.

\section{REFERENCES}

[1] B. K. Bose, "Power electronics and motor drives recent progress and perspective," IEEE Trans. Ind. Electron., Vol. 56, No. 2, pp. 581-587, Feb. 2009.

[2] N. Mohan et. al., "NSF-sponsored faculty workshops on teaching of power electronics and electric drives," Journal of Power Electronics, Vol. 2, No. 4, pp. 231-239, Oct. 2002.

[3] F. Blaabjerg, "A power electronics and drives curriculum with projectoriented and problem-based learning: A dynamic teaching approach for the future," Journal of Power Electronics, Vol. 2, No. 4, pp. 240-249, Oct. 2002

[4] U. Drofenik et. al., "A novel interactive power electronics seminar (IPES) developed at the Swiss Federal Institute of Technology (ETH) Zurich," Journal of Power Electronics, Vol. 2, No. 4, pp. 250-257, Oct. 2002.

[5] N. Ertugrul, "Interactive teaching and self-study tools for power electronics," Journal of Power Electronics, Vol. 2, No. 4, pp. 258-267, Oct. 2002.

[6] M. Matsui et. al., "Education of power electronics in Japan," Journal of Power Electronics, Vol. 2, No. 4, pp. 268-277, Oct. 2002.

[7] N. Mohan et. al., Power Electronics: Converters, Applications and Design, Wiley, New York, 2003.
[8] R. W. Erickson et. al., Fundamentals of Power Electronics, Springer, Berlin, 2000

[9] D. W. Hart, "Circuit simulation as an aid in teaching the principles of power electronics," IEEE Trans. Educ., Vol. 36, No. 1, pp. 10-16, Feb. 1993.

[10] V. F. Pires et. al., "Teaching nonlinear modeling, simulation, and control of electronic power converters using MATLAB/Simulink," IEEE Trans. Educ., Vol. 45, No. 3, pp. 253-261, Aug. 2002.

[11] N. Linge et. al., "Problem-based learning as an effective tool for teaching computer network design," IEEE Trans. Educ., Vol. 49, No. 1, pp. 5-10, Feb. 2006.

[12] R. J. Costa et. al., "Applying the problem-based learning approach to teach elementary circuit analysis," IEEE Trans. Educ., Vol. 50, No. 1, pp. 41-48, Feb. 2007.

[13] N. Hoic-Bozic et. al., "A blended learning approach to course design and implementation," IEEE Trans. Educ., Vol. 52, No. 1, pp. 19-30, Feb. 2009.

[14] A. S. Mantri et al., "Design and evaluation of a PBL-based course in analog electronics," IEEE Trans. Educ., Vol. 51, No. 4, pp. 432-438, Nov. 2008.

[15] E. Allen et al., "Interactive object-oriented simulation of interconnected power systems using Simulink," IEEE Trans. Educ., Vol. 44, No. 1, pp.87-95, Feb. 2001

[16] S. Ayasun et al., "Induction motor tests using MATLAB/Simulink and their integration into undergraduate electric machinery courses," IEEE Trans. Educ., Vol. 48, No. 1, pp.37-46, Feb. 2005.

[17] Texas Instruments - Data sheet of UC3525a http://focus.ti.com/docs/prod/folders/print/uc3525a.html, 2005.

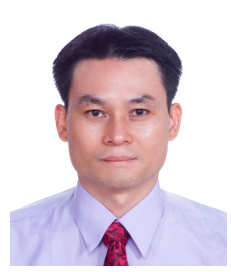

Shun-Chung Wang received the Ph.D. degrees in electrical engineering from National Taiwan University Taipei, Taiwan, in 1995. Currently, he is an Associate Professor with in the Department of Electrical Engineering, Lunghwa University of Science and Technology, Taoyuan, Taiwan. His current research interests include power electronics and their applications.

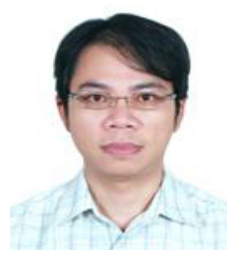

Yih-Chien Chen received the B.S., M.S., and Ph.D. degrees in electrical engineering from National Cheng Kung University, Tianan, Taiwan, in 1994, 1996, an 2000, respectively. He is currently an Associate Professor with in the Department of Electrical Engineering, Lunghwa University of Science and Technology, Taoyuan, Taiwan.

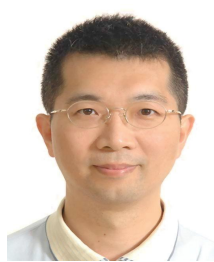

Juing-Huei Su was born in Tainan, Taiwan on February 17, 1965. He received the B.S., M.S., and Ph.D. degrees in electrical engineering from the National Taiwan University, Taipei, in 1987, 1989, and 1993, respectively. From 1993 to 1995 , he served as a Military Officer in the army. In 1995, he was a Senior Engineer in the Taian Electric Company, Ltd., Taiwan. Since 1996, he has been an Associate Professor in the Department of Electronic Engineering, Lunghwa University of Science and Technology, Taiwan. Currently, he is a Professor and the Dean of Student Affairs. His research interests include robust control theory, power electronic systems, and embedded control system implementations. 